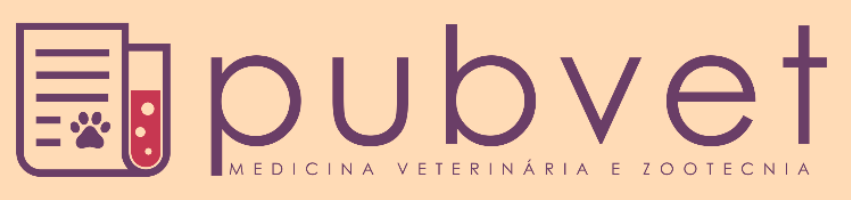

https://doi.org/10.31533/pubvet.v14n1a484.1-7

\title{
Diagnóstico em propriedade de bovino de corte do município de Acrelândia, Acre: estudo de caso
}

\author{
Nayana Jucá Diniz ${ }^{1}$, Wilben Pereira Diniz ${ }^{1} \bullet$, Eduardo Mitke Brandão Reis ${ }^{2 *} \bullet$ \\ ${ }^{1}$ Universidade Federal do Acre, Centro de Ciências Biológicas e da Natureza. Mestrando em Pós-graduação em Produção e Sanidade Animal \\ na Amazônia Ocidental. - Rio Branco, Acre. Brasil. \\ ${ }^{2}$ Universidade Federal do Acre, Centro de Ciências Biológicas e da Natureza. Doutor em Ciências Veterinária. Rio Branco, AC, Brasil. \\ * Autor Correspondência, E-mail: edumitke@gmail.com
}

\begin{abstract}
Resumo. Objetivou-se verificar e descrever os principais pontos fracos apresentados por um sistema de produção de bovinos de corte e organizar os aspectos relevantes que devem ser alterados para o aumento da produtividade pelas ferramentas de gestão. Os dados coletados são resultados de uma propriedade, localizada em Acrelândia, Acre, no período de junho de 2019, sendo coletados a partir de um formulário semiestruturado, contendo 152 questões. As respostas foram obtidas por meio da observação, bem como por entrevista com o proprietário. Utilizando-se a matriz GUT, os principais pontos fracos encontrados, em ordem decrescente: animais doentes juntos aos sadios, ausência de controle do peso ao nascer e a desmama e escolha visual dos touros. Frente a análise dos fatores apresentados, torna-se favorável a aplicação de métodos de planejamento em curto prazo, permitindo maior eficiência econômica e produtiva de modo geral.
\end{abstract}

Palavras chave: Ferramentas de gestão, pecuária de corte, matriz GUT, planejamento

\section{Diagnosis of beef cattle in the municipality of Acrelândia, Acre: case study}

\begin{abstract}
The objective was to verify and describe the main weaknesses presented by a beef cattle production system and to organize the relevant aspects that should be altered to increase productivity through management tools. The data collected are results of a property, located in Acrelândia, Acre, in the period of June 2019., being collected from a semi-structured form, containing 152 questions. Responses were obtained through observation as well as by interview with the owner. Using the GUT matrix, the main weaknesses found, in descending order: sick animals together with healthy animals, lack of birth weight control and weaning and visual choice of bulls. Given the analysis of the factors presented, the application of short-term planning methods is favorable, allowing greater economic and productive efficiency in general.
\end{abstract}

Keywords: Management tools, cattle breeding, matrix GUT, planning

\section{Diagnóstico en propiedad de bovino de corte del municipio de Acrelândia, Acre: estudio de caso}

Resumen. El objetivo de este trabajo fue verificar y describir las principales debilidades presentadas por un sistema de producción de ganado vacuno y organizar los aspectos relevantes que deben ser modificados para aumentar la productividad a través de herramientas de gestión. Los datos recopilados son resultados de una propiedad, ubicada en Acrelândia, Acre, en el período de junio de 2019, siendo recopilados de un formulario semiestructurado conteniendo 152 preguntas. Las respuestas se obtuvieron a través de la observación, así como por entrevista con el propietario. Usando la matriz GUT, las 
principales debilidades encontradas, en orden descendente: animales enfermos junto con animales sanos, falta de control de peso al nacer y destete y elección visual de los toros. Dado el análisis de los factores presentados, la aplicación de métodos de planificación a corto plazo es favorable, permitiendo una mayor eficiencia económica y productiva en general.

Palabras clave: Herramientas de gestión, ganadería de carne, matriz GUT, planificación

\section{Introdução}

A pecuária de corte é considerada uma atividade de maior produção e venda comercial no Brasil, sendo este visto como um dos fornecedores de carne bovina com altos índices de qualidade e ocupando o segundo lugar em 2019 como o maior rebanho bovino (ANUALPEC, 2019). Em 2017, o cenário político econômico em relação à pecuária estremeceu, gerando desequilíbrio nos índices da indústria. Mesmo diante da crise, a cadeia produtiva da carne encerrou o ano com um crescimento em exportação de carne em 13\% e 9\% em volume frente a 2016 (ABIEC, 2019). A reestruturação agropecuária em 2018 registrou um crescimento em $11 \%$ em exportação e 7,9\% em volume em relação ao ano anterior (ABIEC, 2019). A pecuária de corte na região norte vem acompanhando os avanços nas transformações pecuaristas. O Acre possui na atividade agropecuária como a principal fonte econômica do estado, além de obter crescimento do rebanho em 35,7\% entre 2012 e 2014, gerando 2,9 milhões de animais em 2015 (Maia, 2018). O estado em 2017 possuía um rebanho estimado de 3.013.614 cabeças, correspondendo a $93 \%$ a corte e dispondo de $1,36 \%$ em participação do rebanho do estado em relação ao Brasil (ANUALPEC, 2019). O crescimento do rebanho nos últimos 11 anos é equivalente a 22,9\%. Em 2018, o rebanho em cabeças estimado é de 2.807.088, de modo que a participação do rebanho em proporção ao Brasil é de 1,36\%. O crescimento nos últimos 10 anos é correspondente a 21,21\% (ABIEC, 2019).

A eficiência nas práticas agropecuárias voltado aos animais de corte favoreceu ao alcance de índices zootécnicos de aprovação elevados tanta na qualidade como no número de exportações de carne. Nota-se a necessidade do enfoque gerencial em propriedades que buscam o desenvolvimento de ferramentas de planejamento que saliente o controle de atividades e gerem lucros (Raupp \& Fuganti, 2014).

Para existir mudanças da situação é importante a conscientização do proprietário e que o mesmo tenha ou busque conhecimentos voltados a atividades. A qualidade de resultados e gerenciamento da produção é o ponto fundamental para o sucesso da propriedade (Ferreira et al., 2005). A presença de uma atividade em gestão satisfatória permite o desenvolvimento do setor agropecuário, permitindo eficiência nas condições socioeconômicas e o alcance de atividades que forneçam maior lucro (Montoro et al., 2013).

Diante da importância do tema e da escassez de artigos científicos sobre gestão e planejamento das propriedades de corte, objetivou-se analisar os principais pontos fracos de um sistema de produção de bovino de corte, utilizando ferramentas de gestão Matriz GUT e posteriormente $5 \mathrm{~W} 2 \mathrm{H}$ no intuito de corrigi-los ou minimiza-los.

\section{Material e métodos}

O estudo foi conduzido em uma fazenda de criação de bovinos de corte no Estado do Acre, município de Acrelândia, no Ramal do Granada 9'55'16" S 6703'43" W. A atividade bovina iniciou-se em 2002. Em 2019 a propriedade possui 2.092 animais da raça Nelore apresentando idades de 1 a 36 meses de ambos os sexos em confinamento a pasto e machos castrados acima de 36 meses semi confinados. Foi utilizado um formulário semiestruturado (Lopes \& Meira, 2016), contendo 152 questões, sendo elas divididas em temas voltados a caracterização do produtor e propriedade, práticas agrícolas, manejo nutricional, infraestrutura, controle zootécnico, identificação dos animais, manejo reprodutivo, melhoramento genético, manejo de bezerros, controle sanitário e questões ambientais voltados ao diagnóstico de propriedades de corte.

A pesquisa obteve o levantamento de pontos positivos e negativos apresentados pela propriedade. Nesta etapa foi realizada a análise do questionário e utilizou-se a ferramenta de gestão Matriz GUT, para definição dos pontos fracos, sendo este um mecanismo utilizado frequentemente pelas empresas e adaptado (Meireles, 2001) para as propriedades rurais visando priorizar os entraves que devem ser 
solucionados pela gestão, bem como para expor a prioridade que certas atividades devem ser realizadas e desenvolvidas (Fáveri \& Silva, 2016). Com essa ferramenta cada membro da equipe multidisciplinar avaliou os pontos vulneráveis de 0 a 5 em escala crescente com objetivo de pontuar a gravidade do problema, de analisar o seu real tamanho e potencial de gerar impactos negativos na propriedade, sendo essa classificação relacionada a problemas graves, urgente e com maior tendência a piorar. O resultado médio da análise definiu o grau de prioridades apresentados pela propriedade. Os pontos fracos foram listados para análise através do método 5W2H (Veiga et al., 2013). O procedimento consiste em responder todos os questionamentos essenciais para o planejamento dos fatores apresentados (Aguiar, 2006; Oliveira, 1996). No estudo foi utilizada a estatística simples, estimando média e desvio padrão.

\section{Resultados e discussão}

De acordo com Aguiar (2006) e Oliveira \& Campos (2015), as soluções destas questões estão unidas e ao final do preenchimento desta planilha, destaca-se um plano de ação circunstanciado e com fácil entendimento e visualização em que são propostas as ações decididas, de que forma e quais os responsáveis pela execução destas. Com a utilização desta ferramenta, a quantidade de dúvidas ou incertezas será eliminada no planejamento, pois a ferramenta possibilita uma resposta bem clara de quem, onde, quando, por que, como e quanto custa para resolver o problema, pois um erro de informação pode acarretar em muitos prejuízos para a propriedade rural.

Para solucionar os problemas pontuados foi proposta a ferramenta de gestão $5 \mathrm{~W} 2 \mathrm{H}$ descrita na (Quadro 1) (Lisbôa \& Godoy, 2012).

Quadro 1. Etapas para aplicação da ferramenta 5W2H. Fonte: Adaptado de Lopes \& Meira (2016).

\begin{tabular}{|c|c|c|}
\hline What & \multirow{5}{*}{$5 \mathrm{~W}$} & O que? \\
\hline Who & & Quem? \\
\hline Where & & Onde? \\
\hline When & & Quando ${ }^{2}$ \\
\hline Why & & Por quê? \\
\hline How & \multirow{2}{*}{$2 \mathrm{H}$} & Como? \\
\hline How much & & Quanto custa? \\
\hline
\end{tabular}

\section{Ferramenta proposta para solucionar os três pontos fraco: $5 \mathrm{~W} 2 \mathrm{H}$}

Dentre todos os pontos negativos apresentados, pode-se destacar em especial a presença de animais doentes junto aos sadios (Tabela 1), a falta do controle de peso ao nascer e a desmama e a escolha do touro por método visual.

Tabela 1. Pontos Desfavoráveis encontrados na propriedade

\begin{tabular}{|c|c|c|c|c|c|c|}
\hline \multirow{2}{*}{ Pontos fracos } & \multicolumn{3}{|c|}{ Média das notas dos pesquisadores } & \multirow{2}{*}{ Mult } & \multirow{2}{*}{ Média } & \multirow{2}{*}{ DP } \\
\hline & G & $\mathrm{U}$ & $\mathrm{T}$ & & & \\
\hline Animais doentes são não separados dos sadios & 4,7 & 4,7 & 5,0 & 108,9 & 4,8 & 0,19 \\
\hline Falta do controle de peso ao nascer e peso a desmama & 5,0 & 4,0 & 4,7 & 93,3 & 4,6 & 0,51 \\
\hline Escolha visual dos touros & 4,3 & 3,7 & 3,7 & 58,3 & 3,9 & 0,38 \\
\hline Não aduba pastagem & 3,0 & 3,3 & 3,0 & 30,0 & 3,1 & 0,19 \\
\hline Cocho não é coberto & 3,0 & 2,3 & 3,3 & 23,3 & 2,9 & 0,51 \\
\hline Invasora de pastagem & 2,7 & 2,7 & 3,0 & 21,3 & 2,8 & 0,19 \\
\hline Não possui irrigação & 2,3 & 2,3 & 3,0 & 16,3 & 2,6 & 0,38 \\
\hline Não utiliza prática de conservação de forrageiras & 3,0 & 2,3 & 2,3 & 16,3 & 2,6 & 0,38 \\
\hline Não Utiliza algum tipo de software & 1,0 & 1,0 & 1,0 & 1,0 & 1,0 & 0,00 \\
\hline
\end{tabular}

\section{Animais doentes não são separados dos sadios}

Os sistemas de criação de animais exigem condições saldáveis, bem como, um manejo sanitário adequado, mesmo após a obtenção de um sistema com condições ideais o mesmo permanece suscetível 
a possíveis mudanças. Logo, requer permanente vigilância sanitária e controle epidemiológico, seja para patologias consideradas epidêmicas, da mesma maneira que infecções endêmicas (Pires, 2010). Para Vieira \& de Quadros (2008) a saúde e o bem-estar são aspectos de elevada importância e indispensável para o manejo nos sistemas de produção, ademais separar os animais doentes dos sadios facilita o controle e impede a disseminação de doenças e quando aliada a tratamento adequado e prevenção dos demais podendo inclusive erradicar algumas enfermidades da propriedade. Destacam-se outros fatores que constitui o manejo sanitário como a vacinação, controle de parasitas, limpeza dos animais e instalações, em conjunto com ações de prevenção e tratamentos dos animais.

Com relação às patologias infectocontagiosas que limita a reprodução animal no Brasil, Nascimento \& Santos (2000) citaram muitos casos de fêmeas bovinas apresentando as seguintes doenças: para o Herpervírus bovino tipo 1 (BoHV-1) (causador de rinotraqueíte infecciosa bovina), para o vírus causador da diarreia viral bovina (BVD) e para Leptospira hardjo (causadora de leptospirose).

Dentre as doenças inflamatórias e parasitoses mais encontradas por Lucena et al. (2010) estavam a tuberculose, actinomicose, raiva, enterite bacteriana, actinobacilose, abscessos, pneumonias, doenças parasitárias.

a) What (o que?): Animais doentes não são separados dos sadios.

b) When (quando?): após a manutenção do piquete, no máximo em uma semana.

c) Who (quem?): capataz responsável pelo sistema de produção.

c) Where (onde?): Os animais que apresentam alguma enfermidade ficarão no piquete que será construído próximo da residência do capataz para que facilite a observação de alguma manifestação clínica.

d) Why (por quê?): Prevenir a infestação de doenças.

E) How (Como?): aparatando os animais doentes.

f) How Much (quanto custa?): custo zero, já existe o piquete que necessita apenas de manutenção simples.

\section{Falta do controle de peso ao nascer e peso a desmama}

O crescimento do bezerro, especialmente suas medidas no início do desenvolvimento do animal, como peso ao nascer e o peso ao desmame, podem ser bons métodos de escolha para elevar a produtividade de forma eficiente (Ferraz Filho et al., 2002).

Na escolha de bovinos de corte são levados em consideração como critério de seleção, com maior relevância, características de produção, bem como pesos atingidos em idades distintas, como, por exemplo, peso ao nascer e peso a desmama (Boligon et al., 2013). Essas medidas são de obtenção acessível, expondo correlações favoráveis com diversas características de desejo econômico, ademais de responderem à seleção individual, apresentando herdabilidade mediana. Logo reduzindo o efeito do ambiente sobre essas características destacada principalmente em bovinos de corte, como na raça Nelore.

Pesquisas desenvolvidas por Guimarães et al. (2002) e Sala et al. (2009) expressaram que bezerros selecionados a partir de rebanhos para maior ganho de peso a desmama, apresentam grande relação com o produto final, definido pelo peso do animal adulto. Deste modo, o controle de peso pode ser usado como critérios de seleção para permanência ou descartes das matrizes e dos touros da composição do rebanho da propriedade (Vaz et al., 2004).

Juntamente com o crescimento da atividade de criação de bovinos, torna-se necessário aperfeiçoar o plantel tornando-se mais competitivo dentro do mercado, buscando alternativas de agregar aptidão de valor econômico. O ganho de peso em curto espaço de tempo é, certamente, uma das capacidades que mais se buscam. Mediante desta característica elevando o aumento de peso, reduzindo o período dos animais na propriedade reduzindo os gastos com mantença, tendo um animal mais precoce para $\mathrm{o}$ abate (Cerdótes et al., 2004; Costa et al., 2002; Restle et al., 2002; Restle et al., 2003).

a) What (o que?): Controle de peso.

b) When (quando?): de acordo com o nascimento e a desmama dos lotes.

c) Who (quem?): o capataz da propriedade juntamente com os peões.

c) Where (onde?): Na balança que fica no curral. 
d) Why (por quê?): Melhorar o acompanhamento do ganho de peso dos animais.

E) How (Como?): pesando.

f) How Much (quanto custa?): O custo será zero tendo em vista que já existe uma balança na propriedade que não está sendo usada.

\section{Escolha de touro sem registro}

Podemos considerar a reprodução o principal fator da cadeia produtiva da carne bovina, pois por meio da reprodução que se torna possível o nascimento dos bezerros (Pires, 2010; Prado, 2010). Segundo Ferraz Filho et al. (2002), na pecuária de corte características como o crescimento, o peso corporal, as dimensões na fase inicial do desenvolvimento do bezerro, são extremamente importantes no propósito da rentabilidade e devem ser avaliadas como critérios de seleção para a escolha dos reprodutores que serão usados no rebanho.

Ao optar por touros que passaram por avaliação de programa de melhoramento genético, tende ter elevada credibilidade no que tange as características genéticas do animal, podendo garantir ao pecuarista que aglomere ganho em seus descendentes (Grupioni et al., 2015; Yokoo et al., 2009). Portanto, algumas características reprodutivas do touro como precocidade sexual, fertilidade e saúde reprodutiva não confirmam exatidão ao animal, tornando fundamental a realização de exame andrológico e manejo sanitário para diagnosticar patologias infecciosas ligadas à reprodução dos touros (Lima et al., 2011; Vale Filho, 1994).

A utilização dos sumários (Tabela 2) de avaliação genética está se tornando comum em meio aos criadores de gado de corte, tendo como principal fator atuar nos processos de seleção, descarte e acasalamento, sendo decisivo na venda de animais, sêmen e embriões. Entretendo, compreender os processos de elaboração dos sumários e suas variações, e como realizar a aplicação deste mecanismo, é decisivo na escolha de touros para reprodução das propriedades. No Brasil, principalmente para a raça Nelore uma das raças mais usadas no país existe inúmeros sumários onde são expostas estimativas de avaliações genéticas (Silva, 2013).

Tabela 2. Características avaliadas no sumário do programa GenePlus da EMBRAPA gado de corte.

\begin{tabular}{|c|c|c|c|}
\hline \multirow{5}{*}{$\mathrm{kg}$} & \multirow{5}{*}{ Pesos } & Nascimento (PN) & $\mathrm{Kg}$ \\
\hline & & Fase Materna (P120) & $\mathrm{Kg}$ \\
\hline & & Desmama (PD) & $\mathrm{kg}$ \\
\hline & & Sobreano (PS) & $\mathrm{kg}$ \\
\hline & & Ganho de peso pós-desmama (GPD) & $\mathrm{kg}$ \\
\hline \multirow{4}{*}{ Reprodução } & & Habilidade de Permanência (HP/STAY) & $\%$ \\
\hline & & Perímetro escrotal ao Sobreano (PES) & $\mathrm{cm}$ \\
\hline & & Idade ao primeiro parto (IPP) & dias \\
\hline & & Peso da vaca a desmama (PVD) & $\mathrm{Kg}$ \\
\hline \multirow{2}{*}{$\begin{array}{l}\text { Avalição } \\
\text { Subjetiva }\end{array}$} & \multirow{2}{*}{$\begin{array}{l}\text { Conformação } \\
\text { frigorífica }\end{array}$} & Desmama (CFD) & escala 1 a 6 \\
\hline & & Sobreano (CFS) & escala 1 a 6 \\
\hline \multirow{3}{*}{\multicolumn{2}{|c|}{ Medidas por Ultrassonografia }} & Área de olho de lombo (AOL) & $\mathrm{cm}^{2}$ \\
\hline & & Espessura de gordura subcutânea (EGS) & $\mathrm{dm}$ \\
\hline & & Marmoreio (MAR) & $\%$ \\
\hline
\end{tabular}

Fonte: Geneplus (2019).

a) What (o que?): Escolha de touro sem registro.

b) When (quando?): após a venda dos touros não registrados.

c) Who (quem?): Zootecnista que presta assistência à propriedade.

c) Where (onde?): Leilão e com vendedores de touros.

d) Why (por quê?): Melhorar o acabamento na engorda agregando valor.

E) How (Como?): Adquirindo touros registrados.

f) How Much (quanto custa?): O valor arrecadado com a venda dos touros será investido na aquisição de novos. 


\section{Conclusão}

A utilização das ferramentas em gestão agrega índices competitivos de qualidade e valor às propriedades. A reestruturação do controle elaborado por um plano de ação fornece ao empresário participação ativa no mercado. O questionário utilizado proporcionou o levantamento de concepções dos profissionais frente à propriedade, permitindo além da pontuação e classificação dos problemas, mas uma visão do que precisa ser feito primeiro, de como e quando executar ações para enfrentar os desafios em sua fazenda. Pode-se constatar a importância da utilização do questionário devidamente implementado, sendo este uma referência para novas pesquisas. As vantagens das ferramentas em gestão na elaboração de estratégias aumentam a confiabilidade e satisfação dos clientes, gerando uma continua melhoria nos índices de produção e um decréscimo nos recursos desperdiçados, sendo estes fatores chave no desenvolvimento da propriedade de modo geral.

\section{Referências bibliográficas}

ABIEC. (2019). Associação Brasileira das Indústrias Exportadoras de Carnes. Exportações Brasileiras de Carne Bovina - Brazilian Beef Exports. Brasília, Brasil: Governo brasileiro.

Aguiar, S. (2006). Integração das ferramentas da qualidade ao PDCA e ao Programa 6 Sigma. Nova Lima: Tecnologia e Serviços LTDA., 1205-206.

ANUALPEC. (2019). Anuário da Pecuária Brasileira (20th ed. Vol. 1). São Paulo, São Paulo, Brasil: Instituto FNP.

Boligon, A. A., Sala, V. E., Mercadante, M. E. Z., Ribeiro, E. G., Cyrillo, J. N. S. G. \& Albuquerque, L. G. (2013). Parâmetros genéticos para diferentes relações de peso ao nascer e à desmama em vacas da raça Nelore. Ciência Rural, 43(4):676-681. doi: http://dx.doi.org/10.1590/S010384782013005000019.

Cerdótes, L., Restle, J., Alves Filho, D. C., Pacheco, P. S., Missio, R. L. \& Garagorry, F. C. (2004). Desempenho de bezerros de corte filhos de vacas submetidas a diferentes manejos alimentares, desmamados aos 42 ou 63 dias de idade. Revista Brasileira de Zootecnia, 33(3):597-609.

Costa, E. C., Restle, J., Pascoal, L. L., Vaz, F. N., Alves Filho, D. C. \& Arboitte, M. Z. (2002). Desempenho de novilhos Red Angus superprecoces, confinados e abatidos com diferentes pesos. Revista Brasileira de Zootecnia, 31(1):129-138.

Fáveri, R. \& Silva, A. (2016). Método GUT aplicado à gestão de risco de desastres: uma ferramenta de auxílio para hierarquização de riscos. Revista Ordem Pública, 9(1):93-107.

Ferraz Filho, P. B., Ramos, A. A., Silva, L. O. C., Souza, J. C., Alencar, M. M. \& Malhado, C. H. M. (2002). Tendência genética dos efeitos direto e materno sobre os pesos à desmama e pós-desmama de bovinos da raça Tabapuã no Brasil. Revista Brasileira de Zootecnia, 31(2):635-640.

Ferreira, I. C., Silva, M. A., Reis, R. P., Euclides Filho, K., Figueiredo, G. R., Fridrich, A. B., . . FelipeSilva, A. S. (2005). Análise de sensibilidade da margem bruta da receita e dos custos do confinamento de diferentes grupos genéticos. Arquivo Brasileiro de Medicina Veterinaria e Zootecnia, 57(1):93103.

GENEPLUS - Programa Embrapa de Melhoramento Genético de Bovinos de Corte. Disponível em <http://geneplus.cnpgc.embrapa.br/sumarios/nelore2018/index.php> Acesso em: 06 de julho de 2019.

Grupioni, N. V., Guidolin, D. G. F., Venturini, G. C., Lôbo, R. B. \& Munari, D. P. (2015). Parâmetros genéticos e tendências genéticas para características reprodutivas e de crescimento testicular em bovinos guzerá. Revista Caatinga, 28(2):152-160. doi: http://periodicos.ufersa.edu.br/revistas/index.php/sistema.

Guimarães, J. D., Alves, N. G., Costa, E., Silva, M. R., Costa, F. M. J. \& Zamperlini, B. (2002). Eficiências reprodutiva e produtiva em vacas das raças Gir, Holandês e cruzadas Holandês x Zebu. Revista Brasileira de Zootecnia, 31(2):641-647.

Lima, F. P. C., Bergmann, J. A. G., Xavier, P. R. \& Marques Júnior., A. P. (2011). Características zootécnicas de touros da raça Nelore submetidos a um programa de seleção para precocidade sexual. Arquivo Brasileiro de Medicina Veterinária e Zootecnia, 63(6):1303-1308. 
Lisbôa, M. d. G. P. \& Godoy, L. P. (2012). Aplicação do método 5W2H no processo produtivo do produto: a joia. Iberoamerican Journal of Industrial Engineering, 4(7):32-47.

Lopes, F. H. \& Meira, W. (2016). Estudo de caso de um sistema de produção da bovinocultura de corte aplicado uma análise de swot na propriedade estrela, município de Jaru/RO. Rondônia, Brasil.

Lucena, R. B., Pierezan, F., Kommers, G. D., Irigoyen, L. F., Fighera, R. A. \& Barros, C. S. L. (2010). Doenças de bovinos no Sul do Brasil: 6.706 casos. Pesquisa Veterinária Brasileira, 30(5):428-434.

Maia, G. F. N. (2018). Desempenho produtivo de dois grupos genéticos de bovinos de corte em pastos puros e consorciados na Amazônia Ocidental. Master of Science, Universidade Federal do Acre. Rio Branco Acre. Março., Rio Branco, Acre, Brasil.

Meireles, M. (2001). Ferramentas administrativas para identificar observar e analisar problemas (Vol. 2). São Paulo: Arte \& Ciência.

Montoro, S. B., Santos, D. F. L. \& Lucas Júnior, J. (2013). Análise econômica de investimentos que visam à produção de biogás e biofertilizante por meio de iodigestão anaeróbia na bovinocultura de corte. Revista Eletrônica Mestrado em Administração, 123-34.

Nascimento, E. F. \& Santos, R. L. (2000). Patologia da reprodução dos animais domésticos. Rio de Janeiro: Grupo Gen-Guanabara Koogan.

Oliveira, N. C. T. \& Campos, R. M. L. (2015). Utilização das ferramentas de gestão de qualidade em frigorífico de abate de bovinos para exportação. Revista Eletrônica Nutritime, 12(2):4016-4029.

Oliveira, S. T. (1996). Ferramentas para o aprimoramento da qualidade. São Paulo, Brasil: Editora Pioneira.

Pires, A. V. (2010). Bovinocultura de Corte (Vol. 1). Piracicaba, São Paulo: FEALQ.

Prado, I. N. (2010). Produção de bovinos de corte e qualidade da carne (Vol. 1). Maringá, Paraná, Brasil: Eduem.

Raupp, F. M. \& Fuganti, E. N. (2014). Gerenciamento de custos na pecuária de corte: Um comparativo entre a engorda de bovinos em pastagem e em confinamento. Custos e Agronegócio, 10282-316.

Restle, J., Neumann, M., Brondani, I. L., Alves Filho, D. C., Souza Da Silva, J. H., Gonçalves, J. M. \& Kuss, F. (2002). Produção do superprecoce a partir de bezerros desmamados aos 72 ou 210 dias de idade. Revista Brasileira de Zootecnia, 31(4):1803-1813.

Restle, J., Pacheco, P. S., Moletta, J. L., Brondani, I. L. \& Cerdótes, L. (2003). Grupo genético e nível nutricional pós-parto na produção e composição do leite de vacas de corte. Revista Brasileira de Zootecnia, 32(3):585-597. doi: http://dx.doi.org/10.1590/S1516-35982003000300010.

Sala, V. E., Albuquerque, L. G., Mercadante, M. E. Z., Boligon, A. A. \& Bonilha, S. F. M. (2009). Eficiência produtiva em vacas da raça Nelore. Boletim de Indústria Animal, 66(2):107-113.

Silva, L. O. C Melhoramento genetico aplicado em gado de corte. 1. ed. Brasília, 2013.

Vale Filho, V. R. (1994). Seleção de touros e matrizes, em estação de monta, para alta eficiência reprodutiva. Paper presented at the ABCZ, Uberaba, Minas Gerais, Brasil.

Vaz, F. N., Restle, J., Vaz, R. Z., Brondani, I. L., Pádua, J. T., Pacheco, P. S. \& Santos, A. P. (2004). Ganho de peso antes e após os sete meses no desenvolvimento e características quantitativas da carcaça de novilhos Nelore abatidos aos dois anos. Revista Brasileira de Zootecnia, 33(4):1029-1038.

Veiga, R. S., Polacinski, É., Silva, V. B., Tauchen, J. \& Pires, M. R. (2013). Implantação dos 5Ss e proposição de um SGQ para uma indústria de erva-mate. Revista ADMPG, 6(1):71-78.

Vieira, G. A. \& de Quadros, D. G. (2008). O manejo sanitário e sua importância no novo contexto do agronegócio da produção de pecuária de corte. Salvador, Bahia, Brasil: UNEB.

Yokoo, M. J. I., Werneck, J. N., Pereira, M. C., Albuquerque, L., Koury Filho, W., Sainz, R. D., .. . Araújo, F. (2009). Correlações genéticas entre escores visuais e características de carcaça medidas por ultrassom em bovinos de corte. Pesquisa Agropecuária Brasileira, 44(2):197-202.

Recebido: 9 de agosto, 2019.

Aprovado: 1 de novembro, 2019.

Publicado: 29 de fevereiro, 2020

Licenciamento: Este artigo é publicado na modalidade Acesso Aberto sob a licença Creative Commons Atribuição 4.0 (CC-BY 4.0), a qual permite uso irrestrito, distribuição, reprodução em qualquer meio, desde que o autor e a fonte sejam devidamente creditados. 